\title{
Performance analysis of ultra-wideband RF switch using discrete PIN diode in SC-79 package for medical application of microwave imaging
}

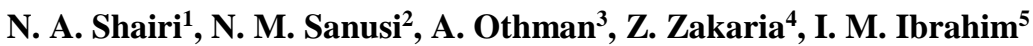 \\ 1,2,4,5 Microwave Research Group (MRG), Centre for Telecommunication Research and Innovation (CeTRI), \\ Fakulti Kejuruteraan Elektronik dan Kejuruteraan Komputer (FKEKK), \\ Universiti Teknikal Malaysia Melaka (UTeM), Malaysia \\ ${ }^{3}$ Fakulti Teknologi Kejuruteraan Elektrik dan Elektronik (FTKEE), \\ Universiti Teknikal Malaysia Melaka (UTeM), Malaysia
}

\section{Article Info}

Article history:

Received Feb 26, 2019

Revised Apr 11, 2019

Accepted Jun 26, 2019

\section{Keywords:}

Medical application

Microwave imaging

RF switch

Single pole double throw

Ultra-wideband

\begin{abstract}
Microwave imaging is an emerging technology in the medical application which have similar functions as X-ray, Magnetic Resonance Imaging (MRI), and Computed Tomography scan (CT scan). In designing a microwave imaging system for medical application, it can use a monostatic radar approach by transmitting a Gaussian pulse (with an ultra-wideband (UWB) frequency). In this system, eight antennas are required with the support of RF switches. Thus, it is important to get the best performance of UWB RF switch in this application. Therefore, this paper presents the performance analysis of four different RF switch topologies (Design 1, 2, 3 and 4) using discrete PIN diode in SC-79 package. The design was based on single pole double throw (SPDT) switch. As result, Design 2 is the best topology after considering the tradeoff between isolation and return loss performances. Based on the three cascaded SPDT switches of Design 2, the insertion loss was less than $-2 \mathrm{~dB}$ and return loss was more than $-10 \mathrm{~dB}$. Meanwhile, the isolation bandwidth (at the minimum isolation of $-20 \mathrm{~dB}$ ) was from 0.5 to 3.7 $\mathrm{GHz}$ (with $3.2 \mathrm{GHz}$ bandwidth), hence, it could be used in the UWB frequency for medical application of microwave imaging.
\end{abstract}

Copyright $\odot 2019$ Institute of Advanced Engineering and Science. All rights reserved.

\section{Corresponding Author:}

Noor Azwan Shairi,

Microwave Research Group (MRG), Centre for Telecommunication Research \& Innovation (CeTRI),

Fakulti Kejuruteraan Elektronik dan Kejuruteraan Komputer (FKEKK),

Universiti Teknikal Malaysia Melaka (UTeM), Hang Tuah Jaya, 76100, Durian Tunggal, Melaka, Malaysia.

Email: noorazwan@utem.edu.my

\section{INTRODUCTION}

Microwave imaging can be used in civil and industrial application such as indestructible test and evaluation pipe leakage or crack in the wall. This technology also capable to detect buried objects in the shallow subsurface and useful in military for demanding activities. Meanwhile, in medical application, microwave imaging can be used for screening abnormal tissue or tumor inside the human body. Microwave imaging allocated in ultra-wideband (UWB) frequency is needed in this application due to the use of the Gaussian pulse in detecting of any abnormal tissue [1-4] especially for breast cancer. With a few hundred picoseconds of Gaussian pulse, the frequency bandwidth could be in the gigahertz that covered under UWB frequency application.

Figure 1 shows a simplified system for microwave imaging that uses at least eight antennas with RF switches [5]. Monostatic radar approach is technology using one antenna act as both transmitter and receiver and the signal is analyzed by interrogating reflecting signal [6]. Therefore, UWB switching is important to 
switch between antennas to ensure the power signal from the pulse generator reaching to the antenna with minimum losses $[4,7]$. Usually, switch antenna array used half wavelength to approximate actual effective monostatic element position [8]. By controlling using voltage supply, only one antenna is selected at the same time for transmitting and receiving of the pulse signal. The reflected signal will be captured at receiver where an image will be formed by confocal algorithm.

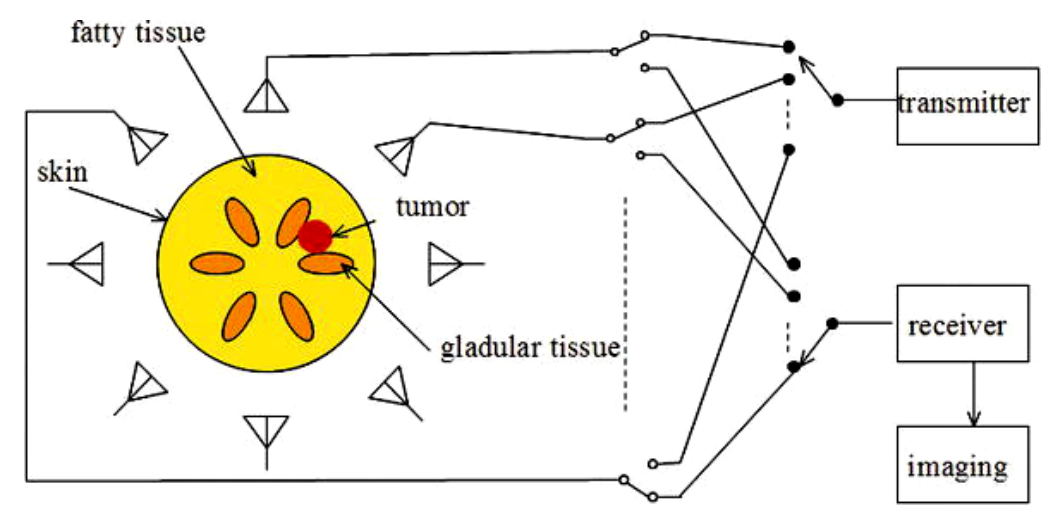

Figure 1. System for microwave imaging that uses at least eight antennas with RF switches [5]

In this paper, the performance analysis of four different RF switch topologies (Design 1, 2, 3 and 4) using discrete PIN diode is presented. The design is based on a single pole double throw (SPDT) switch that build up to be a single pole eight throw (SP8T) to connect with eight antennas. A low-cost discrete PIN diode was chosen that packaged in a standard SC-79 package as depicted in Figure 2. It is a small footprint of plastic packaged from Skyworks Solutions with a part number of SMP1320-079LF [9].

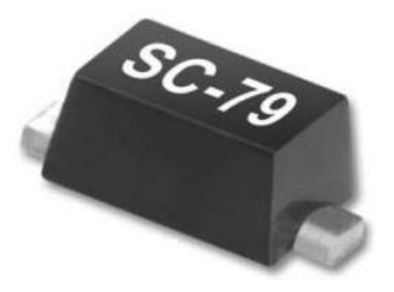

Figure 2. SC-79 package with a dimension of $1.3 \mathrm{~mm}(\max ) \times 0.9 \mathrm{~mm}(\max )$ [9]

\section{UWB RF SWITCH DESIGN}

The proposed RF switch configuration for monostatic microwave imaging is depicted in Figure 3. Seven SPDT switches (becomes SP8T) are required to connect from the transmitter (Tx) and receiver (Rx) to the eight monostatic antennas. Therefore, seven different voltage controls (biasing) are required to control the selection of the antennas. An example, if the signal is transmitted/received at antenna no. 8, then SPDT 1 will be connected to SPDT 3 and to SPDT 7, where it requires three cascaded SPDT switches.

Figure 4 is the detailed topology of SPDT switch. In order to get ultra-wideband insertion loss and isolation, a series-shunt PIN diode is the most chosen configuration by researchers/designers [10-16]. Then, by adding more shunt diodes (Dna and Dnb), isolation can be increased by a maximum of $6 \mathrm{~dB}$ for each additional PIN diode [13].

In the SPDT switch, two different biasing levels ( $5 \mathrm{~V}$ and $-5 \mathrm{~V}$ ) are required to select RF signal from one port to another. In the biasing circuit, DC block is placed in shunt position to allow any unwanted signal frequencies generated by the DC source to be grounded. Meanwhile, DC feed in the biasing circuit prevents any RF frequency to pass through to biasing lines, thus eliminating any RF signal leakage in the SPDT switch. 


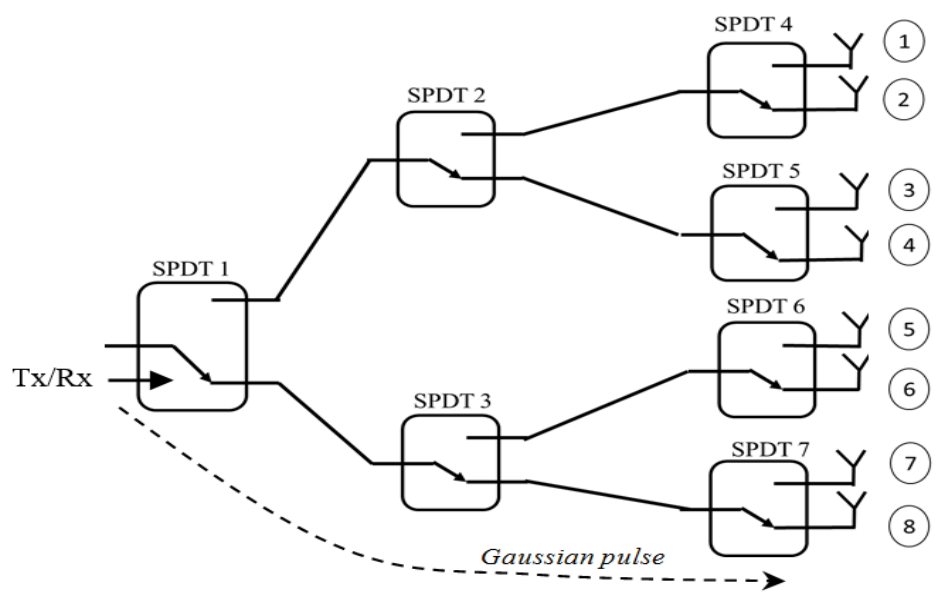

Figure 3. The proposed RF switch configuration for monostatic microwave imaging

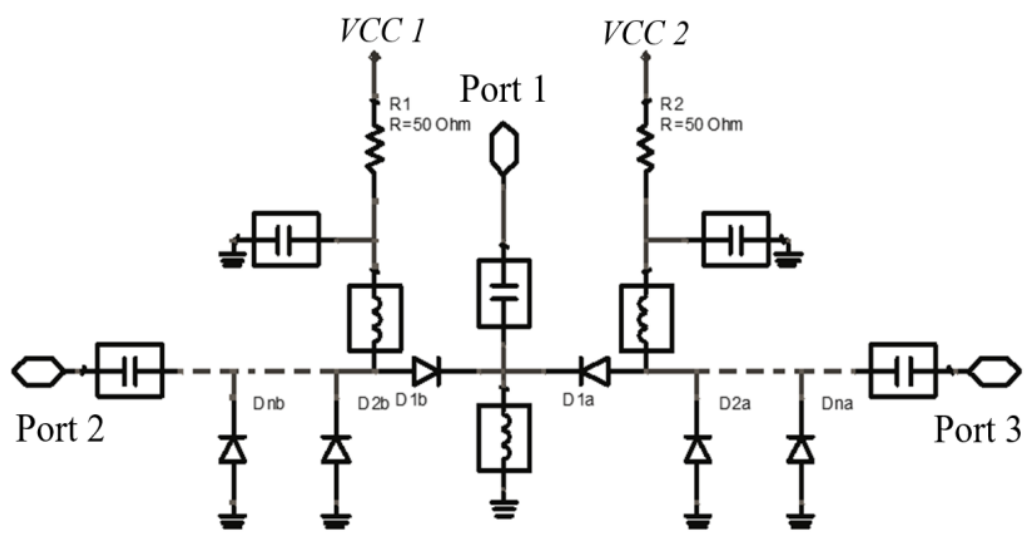

Figure 4. UWB SPDT switch topology [10-16]

Table 1 shows the SPDT switch operation during ON and OFF modes. In this example, during ON mode operation (with $V C C 1=+5 \mathrm{~V}$ ), RF signal passed through from Port 1 to Port 2 . Then the operation of the PIN diodes would be; D1b (series PIN diode) was turned ON and; D2b and Dnb (shunt PIN diodes) were turned OFF. On the other path, during OFF mode operation (with $V C C 2=-5 \mathrm{~V}$ ), RF signal would be blocked from entering from Port 1 to Port 3. Then the operation of the PIN diodes would be; D1a (series PIN diode) was turned OFF and; D2a and Dna (shunt PIN diodes) were turned ON.

Table 1. SPDT Switch Operation

\begin{tabular}{|c|c|c|}
\hline & $\begin{array}{c}\text { ON Mode } \\
\text { Transmit/Receive between Port } 1 \text { and Port } 2\end{array}$ & $\begin{array}{c}\text { OFF Mode } \\
\text { Transmit/Receive between Port } 1 \text { and Port } 3\end{array}$ \\
\hline$V C C 1$ & $+5 \mathrm{~V}$ & NA \\
\hline$V C C 2$ & NA & $-5 \mathrm{~V}$ \\
\hline Dla (series) & NA & OFF state \\
\hline D2a, Dna (Shunt) & NA & ON state \\
\hline Dlb (series) & ON state & NA \\
\hline$D 2 b, D n b$ (Shunt) & OFF state & NA \\
\hline
\end{tabular}

For the analysis of the performance of the UWB SPDT switch for microwave imaging application, four different topologies of SPDT switch were investigated in term of insertion loss, return loss and isolation. The importance of isolation in RF switches was discussed in [17] and the importance of wideband or broadband RF switches was discussed in [18]. As depicted in FigureS 5-8, Design 1 is single series and single shunt PIN diodes, Design 2 is single series and double shunt PIN diodes, Design 3 is single series and triple shunt PIN diodes and Design 4 is single series and quadruple shunt PIN diodes respectively. 
All these four SPDT switch designs were constructed in Advanced Design Software (ADS) by importing the PIN diode model of SMP1320-079LF from Skyworks. Then the performances of insertion loss, return loss and isolation were simulated by using an $S$-parameter simulator.

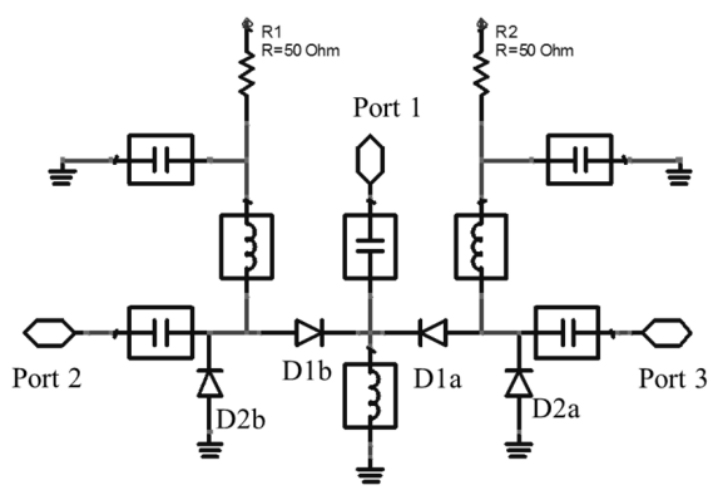

Figure 5. Design 1 - single series and single shunt PIN diodes

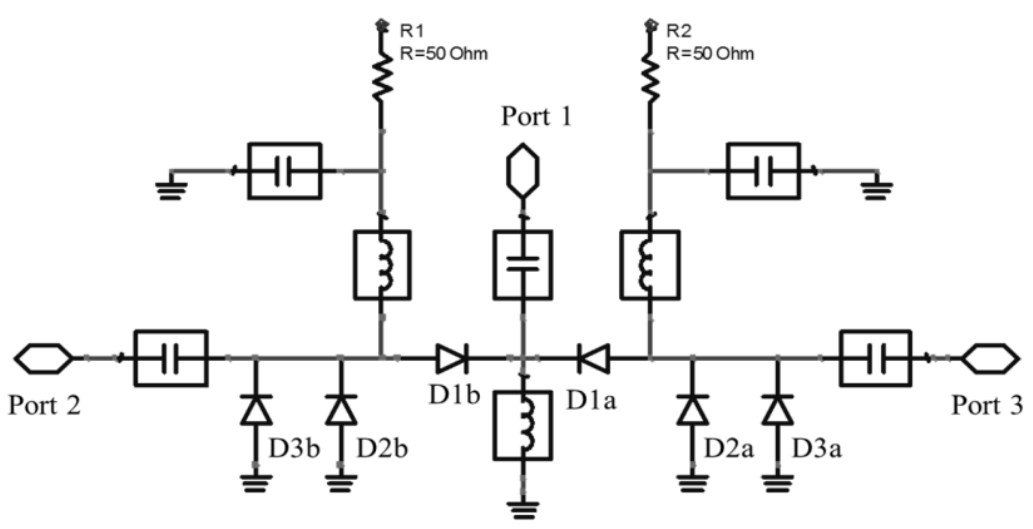

Figure 6. Design 2 - single series and double shunt PIN diodes

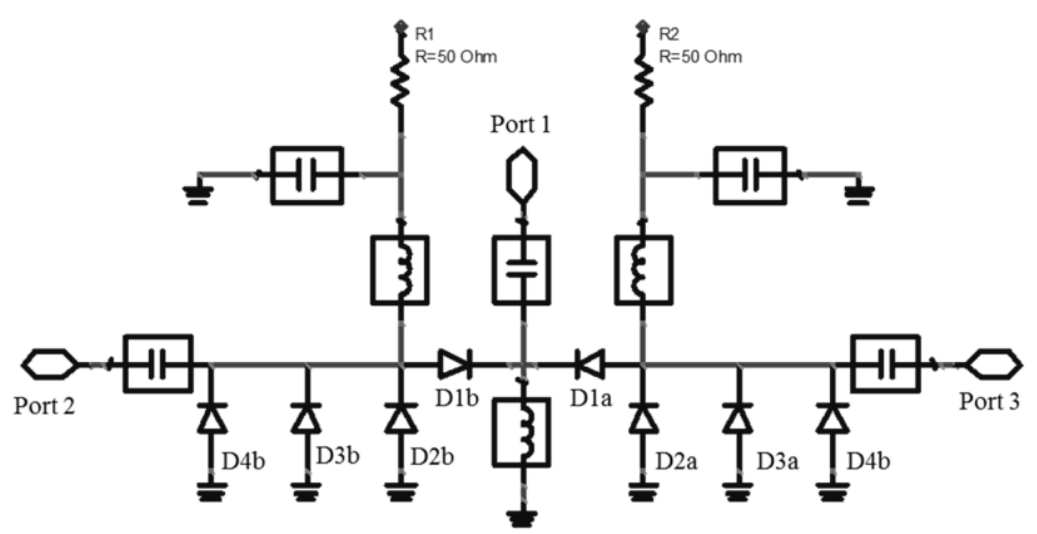

Figure 7. Design 3 - single series and triple shunt PIN diodes 


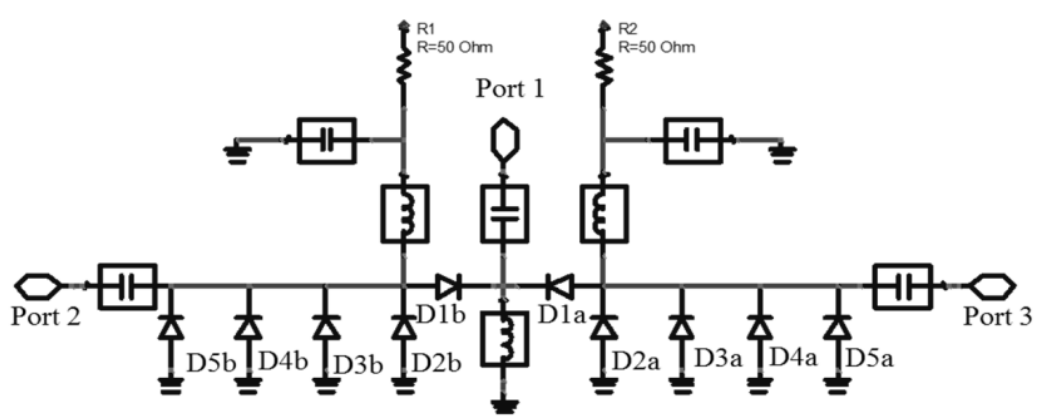

Figure 8. Design 4 - single series and quadraple shunt PIN diodes

\section{RESULTS AND ANALYSIS}

Figure 9, 10 and 11 show the performance results of insertion loss $S(1,2)$, return loss $S(1,1)$ and isolation $\mathrm{S}(1,3)$ respectively. All these four SPDT switch designs for the performance of insertion loss, return loss and isolation are plotted on the same graph for analysis and comparison. It was simulated from 0.5 to 8 $\mathrm{GHz}$ in order to see its capability in the UWB application of microwave imaging. From Figure 9, it was found that by adding a more shunt PIN diode, the insertion loss was reduced at higher frequencies. An instance, at $6 \mathrm{GHz}$, the Design 1 has $-0.7 \mathrm{~dB}$ insertion loss while Design 4 has $-2.5 \mathrm{~dB}$ insertion loss. This is due to additional losses due to the PIN diode in SC-79 package.

From Figure 10, it was found that by adding a more shunt PIN diode, the return loss was reduced almost in the same amount across the frequency range. A significant reduction can be seen between Design 1 and 2 with 4 to $8 \mathrm{~dB}$ difference. It becomes lesser with Design 3 and 4 with 1 to $2 \mathrm{~dB}$ difference. From Figure 11, it was found that by adding a more shunt PIN diode, the isolation was improved almost in the same amount across the frequency range. It can be seen an additional $6 \mathrm{~dB}$ isolation between Design 1 and 2. Meanwhile, less than $6 \mathrm{~dB}$ isolation improvement was experienced between Design 2, 3 and 4.

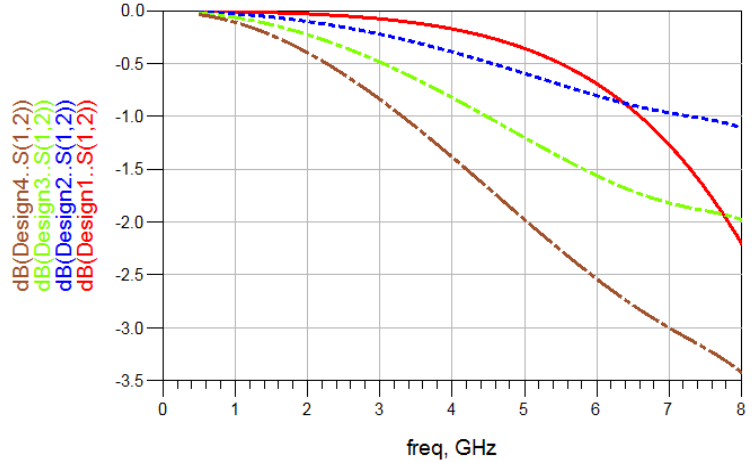

Figure 9. Simulated result of insertion loss

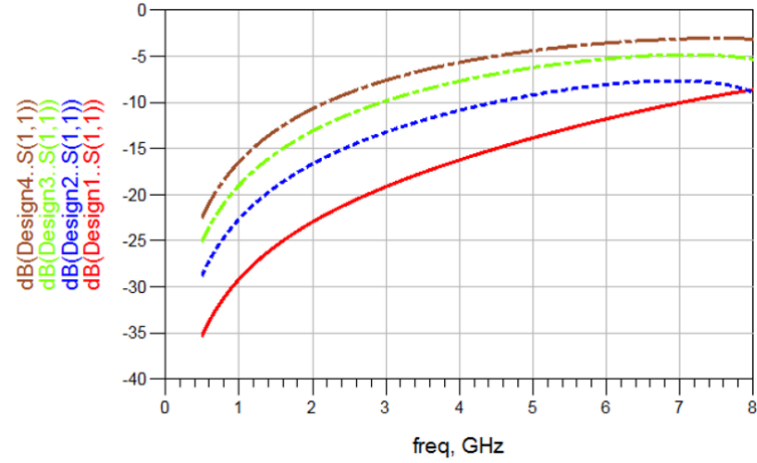

Figure 10. Simulated result of return loss

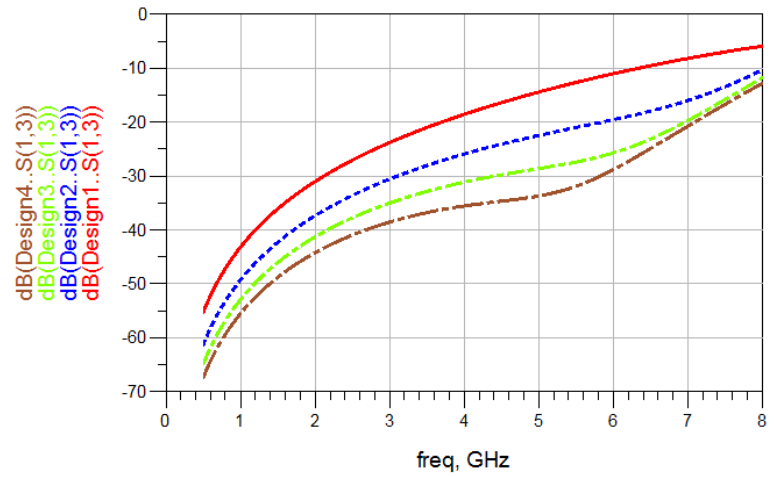

Figure 11. Simulated result of isolation 
Table 2 summarizes the performance comparison of Design 1, 2, 3 and 4. Significantly, it can be observed that there is a trade-off between isolation and return loss. If higher isolation is required, a reduction of return loss will be experienced and limiting the usable RF bandwidth for Gaussian pulse generator in the monostatic based microwave imaging. However, since the transmit power for microwave imaging is very low, for example $0 \mathrm{dBm}$ (or $1 \mathrm{~mW}$ ) [19], thus high isolation with minimum $-20 \mathrm{~dB}$ isolation could be sufficiently enough in eliminating unwanted port to port RF signal. Therefore, if considering a minimum return loss of $-10 \mathrm{~dB}$ in any RF circuit design, Design 2 is the best topology for a UWB SPDT switch. However, by referring Figure 10 and 11, the usable bandwidth (a trade off between isolation and return loss) was $4 \mathrm{GHz}$ (from 0.5 to $4.5 \mathrm{GHz}$ ).

Table 2. Performance Comparison of SPDT Switches from 0 to $7 \mathrm{GHz}$

\begin{tabular}{lccc}
\hline & Insertion Loss $(\mathrm{S} 12)(\mathrm{dB})$ & Return Loss @ Port $1(\mathrm{~S} 11)(\mathrm{dB})$ & Isolation $(\mathrm{S} 13)(\mathrm{dB})$ \\
\hline Design 1 & -0.088 to -1.312 & -35.232 to -10.088 & -55.254 to -8.029 \\
Design 2 & -0.014 to -0.967 & -28.665 to -7.661 & -61.300 to -15.920 \\
Design 3 & -0.024 to -1.829 & -24.974 to -4.844 & -64.819 to -19.245 \\
Design 4 & -0.038 to -2.992 & -22.400 to -3.141 & -67.383 to -20.245 \\
\hline
\end{tabular}

Then, a further performance analysis was carried out on the Design 2 for three cascaded SPDT switches (SPDT $1+$ SPDT $3+$ SPDT 7) as depicted in Figure 3. The simulated results of insertion loss return loss and isolation are shown in Figure 12. It was found that the insertion loss (less than $-2 \mathrm{~dB}$ ) and return loss (more than $-10 \mathrm{~dB}$ ) were in an acceptable value from 0.5 to $6 \mathrm{GHz}$ frequencies. Meanwhile, the isolation bandwidth (at the minimum isolation of $-20 \mathrm{~dB}$ ) was from 0.5 to $3.7 \mathrm{GHz}$ (with $3.2 \mathrm{GHz}$ bandwidth). Hence, the usable bandwidth of the cascaded SPDT switches was limited by the isolation performance. The integration between UWB antennas $[20,21]$ and the proposed UWB switches need to be implemented for the verification of medical application of microwave imaging.

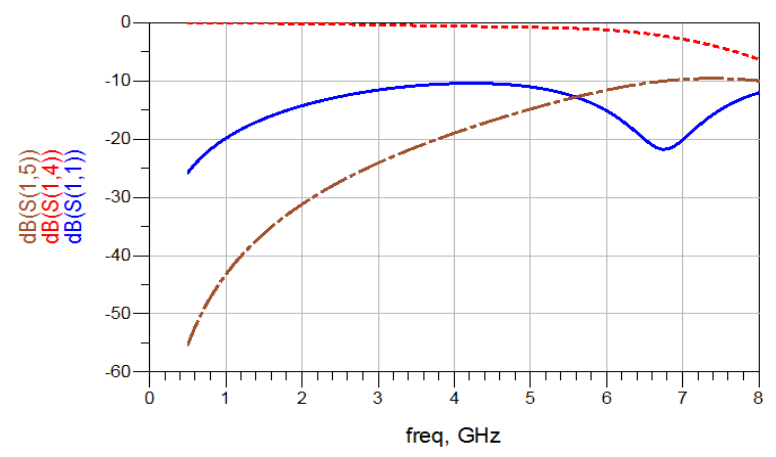

Figure 12. Simulated result for three cascaded SPDT switches of Design 2

\section{CONCLUSION}

In this paper the performance analysis of four RF switch topologies using discrete PIN diode was reported. PIN diode (in SC-79 package) was used to control the switching operation. These four different SPDT topologies were analyzed in terms of insertion loss, return loss and isolation. Therefore, the best topology for the UWB RF switch in medical application is Design 2. Then, based on the three cascaded SPDT switch of the design, the isolation bandwidth (at the minimum isolation of $-20 \mathrm{~dB}$ ) was from 0.5 to 3.7 $\mathrm{GHz}$ (with $3.2 \mathrm{GHz}$ bandwidth). Thus, it could be used in the UWB frequency for medical application of microwave imaging.

\section{ACKNOWLEDGEMENTS}

The authors would like to greatly express their thanks and appreciation to the Centre for Telecommunication Research and Innovation (CeTRI), Centre for Research and Innovation Management (CRIM) and Universiti Teknikal Malaysia Melaka (UTeM) for their encouragement and help to complete this research work. This work was supported by Ministry of Education (MOE) under research grant FRGS/2018/FTKEE-CeTRI/F00383. 


\section{REFERENCES}

[1] Y. Wang, A. E. Fathy and M. R. Mahfouz, "UWB microwave imaging system with a novel calibration approach for breast cancer detection," 2011 IEEE Topical Conference on Biomedical Wireless Technologies, Networks, and Sensing Systems, pp. 63-66, 2011.

[2] Y. Kuwahara and T. Ozaki, "Radar Imaging Using Bilateral Symmetry of Breast Tissue," 2018 48th European Microwave Conference (EuMC), Madrid, pp. 499-502, 2018.

[3] T. Sugitani, S. Kubota, M. Hafiz, A. Toya and T. Kikkawa, "A breast cancer detection system using 198 ps Gaussian monocycle pulse CMOS transmitter and UWB antenna array," 2013 International Symposium on Electromagnetic Theory, pp. 372-375, 2013.

[4] A. Azhari, S. Takumi, S. Kenta, T. Kikkawa and X. Xiao, "A $17 \mathrm{GHz}$ bandwidth $1.2 \mathrm{~mW}$ CMOS switching matrix for UWB breast cancer imaging," 2014 IEEE Biomedical Circuits and Systems Conference (BioCAS) Proceedings, pp. 109-112, 2014.

[5] Kuwahara, Yoshihiko. "Microwave Imaging for Early Breast Cancer Detection." In New Perspectives in Breast Imaging. InTech, 2017.

[6] E. C. Fear, J. Bourqui, C. Curtis, D. Mew, B. Docktor and C. Romano, "Microwave Breast Imaging With a Monostatic Radar-Based System: A Study of Application to Patients," IEEE Transactions on Microwave Theory and Techniques, vol. 61, no. 5, pp. 2119-2128, May 2013.

[7] S. Brovoll, T. Berger, Y. Paichard, Aardal, and T. S. Lande, "Time-Lapse Imaging of Human Heart Motion with Switched Array UWB Radar," IEEE Transactions on Biomedical Circuits and Systems, vol. 8, no. 5, pp. 704-715, 2014.

[8] G. L. Charvat, L. C. Kempel, E. J. Rothwell, C. M. Coleman and E. L. Mokole, "An ultrawideband (UWB) switched-antenna-array radar imaging system," 2010 IEEE International Symposium on Phased Array Systems and Technology, pp. 543-550, 2010.

[9] Skyworks Solutions, Inc. Data Sheet, SMP1320 Series: Low Resistance, Low Capacitance, Plastic Packaged PIN Diodes, 2015.

[10] J. G. Yang, H. Eom, S. Choi and K. Yang, "2-38 GHz Broadband Compact InGaAs PIN Switches using a 3-D MMIC Technology," 2007 IEEE 19th International Conference on Indium Phosphide \& Related Materials, pp. 542-545, 2007.

[11] Q. Li and Y. P. Zhang, "CMOS T/R Switch Design: Towards Ultra-Wideband and Higher Frequency," IEEE Journal of Solid-State Circuits, vol. 42, no. 3, pp. 563-570, 2007.

[12] S. Mou, M. Kaixue, and Y. K. Seng. "A DC to 30-GHz ultra-wideband CMOS T/R switch." Microwave and Optical Technology Letters, vol. 53, no. 9, pp. 2072-2075, 2011.

[13] Algumaei, M. Y.; Shairi, N. A.; Zakaria, Z.; Zobilah, A. M. S.; Ahmad, B. H., "Analysis of Open Stub Resonator and its Application in Dual Isolation Band of SPDT Switch Design," International Journal of Electrical \& Computer Engineering (IJECE), Vol. 6, Issue 6, pp. 2900-2910, Dec 2016.

[14] L. C. Peng, J. G. Shi, Z. R. He, and W. Zou. "DC 10.6 GHz Ultra Wideband SPDT Switch." Advanced Materials Research, vol. 798, pp. 520-525. Trans Tech Publications, 2013.

[15] C. Huynh and C. Nguyen, "New Ultra-High-Isolation RF Switch Architecture and Its Use for a 10-38 GHz 0.18-um BiCMOS Ultra-Wideband Switch," IEEE Transactions on Microwave Theory and Techniques, vol. 59, no. 2, pp. 345-353, 2011.

[16] M. H. Misran, N. A. Shairi, G. H. and M. A. M. Said, "Design and performance analysis of single biasing based SPDT switch for wireless data communications," 2012 IEEE Asia-Pacific Conference on Applied Electromagnetics (APACE), pp. 363-366, 2012.

[17] M. H. Abdul Hadi, B. H. Ahmad, P. W. Wong, and N. A. Shairi. "An overview of isolation improvement techniques in RF switch." ARPN J. Eng. Appl. Sci, vol. 9, no. 3 342-348, 2014.

[18] A. M. S. Zobilah, N. A. Shairi, Z. Zakaria, and M. S. Jawad. "RF switches in wide-, broad-, and multi-band RF front-end of wireless communications: An overview." ARPN J. Eng. Appl. Sci, vol. 11, no. 5, 3244-3248, 2016.

[19] M. A. Toaha, A. Mahmoud, and A. M. Abbosh. "Portable wideband microwave imaging system for intracranial hemorrhage detection using improved back-projection algorithm with model of effective head permittivity," Scientific Reports, vol. 6, 20459, 2016.

[20] Jawad Ali, Roshayati Yahya, Noorsaliza Abdullah, Syarfa Zahirah Sapuan. "Ultra-Wideband Monostatic Antenna for behind the Wall Detection," International Journal of Electrical \& Computer Engineering (IJECE), Vol. 7, Issue 6, pp. 2936 2941, Dec 2017.

[21] S. Elajoumi, A. Tajmouati, J. Zbitou, A. Errkik, A. M. Sanchez, M. Latrach. "Bandwidth enhancement of compact microstrip rectangular antennas for UWB applications," Telecommunication Computing Electronics and Control (TELKOMNIKA), Vol 17, No 3, June 2019. 